\title{
Marcas da ação antrópica na história ambiental do Rio Jaguaribe, Ceará, Brasil *
}

\section{Tracks of anthropic action in the environmental history of the Jaguaribe River, State of Ceará, Brazil}

\author{
Ana Flávia Pantalena ${ }^{\circledR,}$, Luis Parente Maia $^{1}$
}

\begin{abstract}
RESUMO
Localizado na região leste do estado do Ceará, o Rio Jaguaribe representa a maior e mais relevante reserva hídrica cearense. Juntamente com seus tributários mais importantes, os rios Banabuiú e Salgado, formam as bacias do Alto, Médio e Baixo Jaguaribe. Sua bacia hidrográfica abrange aproximadamente $80.000 \mathrm{~km}^{2}$ e compreende praticamente a metade da área do Estado. Apesar da irregularidade hídrica fluvial cearense, o rio Jaguaribe teve um papel de destaque na ocupação e no desenvolvimento econômico do Estado. Através de uma abordagem histórica, desde o início de sua colonização, no século XVII, até os dias de hoje, em conjunto com os elementos naturais e associada aos diversos usos e às várias atividades econômicas desenvolvidas na área, buscou-se apresentar e analisar os diversos impactos decorrentes dessa ocupação, bem como a importância da avaliação dos impactos ambientais de maneira mais integrada e sistêmica, levando-se em consideração os eventuais impactos ambientais residuais e/ou cumulativos gerados isoladamente ou pela somatória das atividades desenvolvidas na região, a fim de prevalecer o uso racional e sustentável do ambiente para as futuras gerações. A presente pesquisa possui características exclusivamente qualitativas, tendo como procedimentos técnicos a pesquisa dos livros históricos e documentos disponíveis, a observação simples, entrevistas e levantamento fotográfico. No que se refere à conclusão desse processo de investigação científica, pode-se considerar que, historicamente, a ocupação das margens do rio Jaguaribe ocorreu levando em consideração tão somente os interesses antrópicos.
\end{abstract}

Palavras-chave: impacto ambiental; desenvolvimento; História Ambiental.

\section{ABSTRACT}

The Jaguaribe River, which is located in Eastern Ceara is the largest and most important reserve of fresh water for the Brazillian state of Ceará The Rivers, Banabuiu and Salgado, along with the most important tributaries of Jaguaribe, form the Upper, Middle, and Lower Jaguaribe watersheds that cover approximately 80,000 km2, and half of the area of the State. An important Environmental Preservation Area (EPA, also known as Área de Preservação Ambiental (APA) in Brazilian Portuguese) is located at the outfall of River Jaguaribe is located. The Canoa Quebrada EPA is internationally known for its natural beauty and tourism potential. The Jaguaribe River belongs to the Atlantic-Western Northeast Hydrographic Regionnamed by the National Water Agency (NWA, also known as Agência Nacional de Águas (ANA) in Brazilian Portuguese), the Federal Regulating Agency and manager of water resources in Brazil. It is uniquely important for the water supply of the State capital, Fortaleza, and its metropolitan area as well as to the State Industrial Park. The importance of its water resources is being currently investigated by the Global International Waters Assessment (GIWA) project, UNEP / GEP (hydrographic area known as Brazilian Northeast - 40a, especially since it is located in a semi-arid state, and environmental pressure is being increasingly caused by the regional economic development. Although the Brazilian government monitors the quality of the

\footnotetext{
@ Corresponding author: <panta3@terra.com.br>

${ }^{1}$ Universidade Federal do Ceará (UFCE), Instituto de Ciências do Mar (LABOMAR), CEP 60165-081, Fortaleza, CE, Brasil.
} 
water and its flow, recent studies on the environmental impact on coastal ecosystems demonstrated a reduced flow of sediments to the sea and changes in their physicochemical characteristics, which cause imbalance and erosion of the coastal zone, besides degradation of mangroves and associated ecosystems. Many impacts, currently perceived on the coast, originate in locations distant from the outfall of the river, or have been caused by activities that occurred in the past, and which continue to affect the entire length of the watershed. Although the irregularity of the river waters of Ceará, which compromises the use of this river as a means of transportation, Jaguaribe had a prominent role in the occupation and economic development of the State. The city of Aracati, located on its outfall, was for long time an important economic, social, and political center of Ceará, in addition to being the main producer and exporter of dried meat (jerky) to sugarcane regions and to having hosted the largest export port of the State (Port of Fortim). Even to this day, some of the most important cities and economic activities of Ceará are located along its banks. The different impacts derived from its occupation, since the beginning of its colonization in the 17th century, until today, were shown and analyzed in this study, together with natural elements, in conjunction with different uses and various economic activities undertaken in the area. Moreover, it was also important to evaluate the environmental impacts in an integrated and systematic manner, considering any potential environmental impacts, residual and / or cumulative, generated separately or by the sum of the activities engaged in the region to propagate the sustainable and rational use of the environment for future generations. This is a qualitative study in which investigation of historical books and documents, simple observations, interviews, and photographic surveys are the main technical procedures. In conclusion, it may be considered that, historically, the occupation of the Jaguaribe River considered only anthropogenic interests.

Keywords: : environmental impact; development; Environmental History.

\section{Introdução}

As margens do rio Jaguaribe, desde o início da colonização do estado do Ceará, foram o centro de muitas atividades sociais e econômicas, tendo sofrido com a intervenção e as formas de ocupação do homem, cada vez mais intensas e capazes de comprometer sua integridade funcional para as futuras gerações. No decorrer do tempo, a ação antrópica sobre os recursos naturais, de um modo geral, tem contribuído para o estado atual de degradação ambiental do nosso planeta e pode colocar em risco o seu uso.

Durante todo o processo de colonização do estado do Ceará, o rio Jaguaribe sempre figurou como um dos principais facilitadores para a penetração e fixação dos colonizadores "sertão adentro", fornecendo os requisitos essenciais à sobrevivência humana: alimento, solo e água (Girão, 1986; Thebérge, 1869).

Com o passar dos séculos a região jaguaribana passou por vários ciclos econômicos, sofrendo diferentes tipos de impactos ambientais em decorrência do acelerado e mal planejado ritmo de expansão e prática agropastoril, açudagem, ocupação urbana, industrialização, gerando problemas, muitas vezes, irreversíveis, capazes de comprometer economicamente e ecologicamente esse importante recurso hídrico cearense (Guerra, 2009; Pinheiro et al., 2009).

Diante da importância do rio Jaguaribe para o Ceará, principal fonte hídrica do Estado, bem como a crescente preocupação quanto à disponibilidade e à qualidade hídrica mundial, faz-se necessário um estudo mais abrangente e sistêmico dos diversos usos a que foi e está sendo submetido este rio, a fim de apontar os principais problemas advindos da inadequada forma de utilização de suas margens desde o início de sua ocupação e possíveis formas de mitigar esses impactos para as futuras gerações.

$\mathrm{O}$ estudo da ocupação da região jaguaribana e das diversas atividades econômicas que fomentaram seu desenvolvimento visa apontar muitos dos impactos ambientais que atingiram direta ou indiretamente a região e refletir acerca das mudanças ambientais originadas a partir da acumulação temporal e espacial gerada por essas atividades, delimitando, assim, o objetivo geral do presente processo de investigação.

Assim, esta pesquisa objetivou: 1) Analisar historicamente os diversos usos do rio Jaguaribe, relacionando sua ocupação/ ciclo econômico com os possíveis impactos ambientais causados pelas atividades antrópicas; 2 ) Caracterizar os impactos ambientais atuais e os possíveis impactos futuros decorrentes das atividades empreendidas no passado e no presente; 3) Ressaltar a importância de se considerar os impactos ambientais residuais e/ou cumulativos, seja na escala temporal ou espacial, nas futuras avaliações e autorizações de usos dessa bacia hidrográfica.

\section{Material e métodos}

\subsection{Enquadramento}

A bacia hidrográfica do rio Jaguaribe está localizada no quadrante leste do estado do Ceará. Seu curso fluvial segue desde o interior, no sentido NNE-SSW (nortenordeste e sul-sudoeste), por uma extensão de $610 \mathrm{~km}$, abrangendo uma área de drenagem de $80.000 \mathrm{~km} 2$. Sua extensa área de drenagem é formada, à direita, pelos rios Carius, Salgado e Figueiredo e, à esquerda, pelos rios:Banabuiú e Palhano. (Figura 1).

A delimitação da área estudada, a partir da divisão territorial do estado do Ceará, está inserida na Mesorre- 


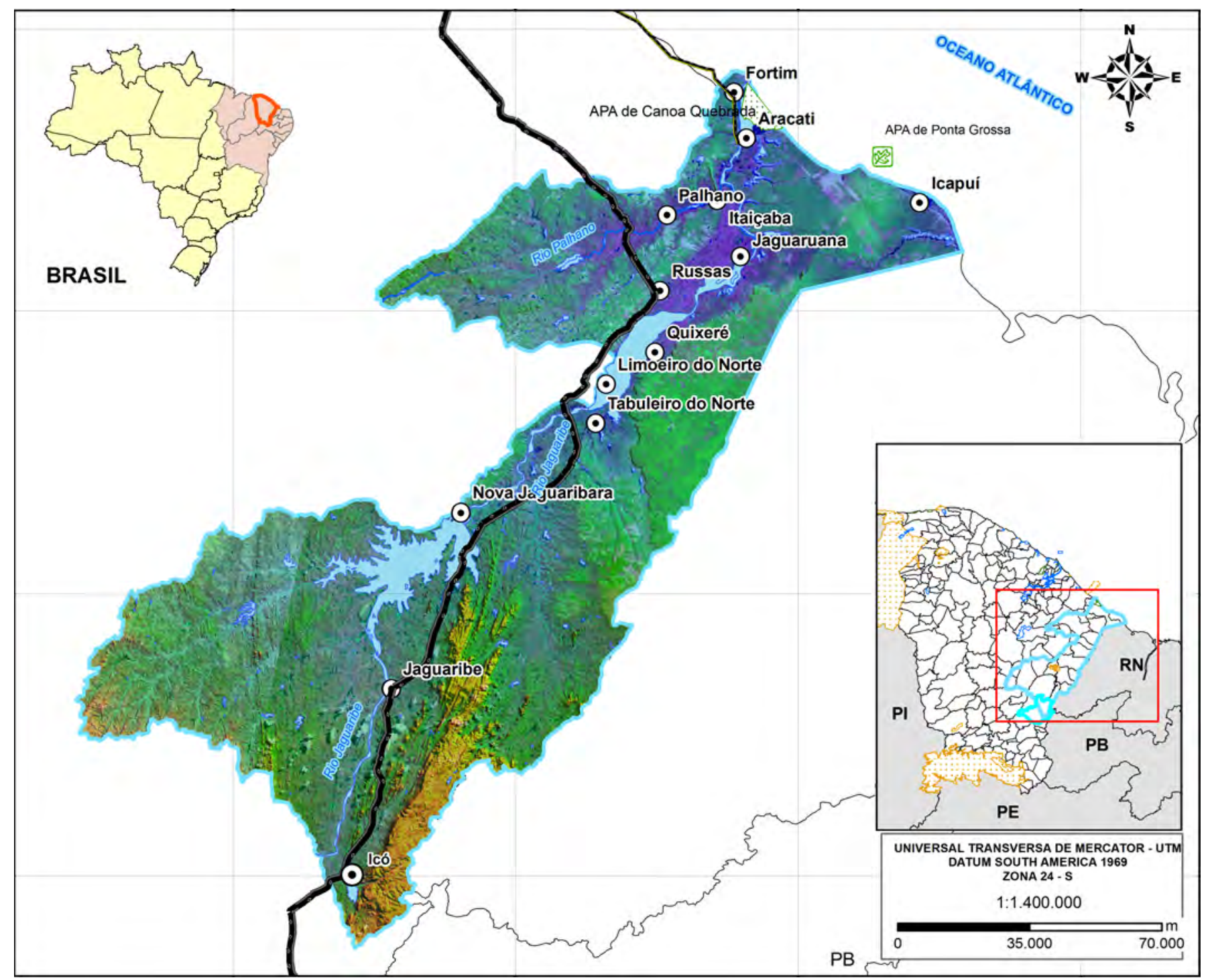

Figura 1 - Localização da área de estudo e acesso (Litoral Leste, Estado do Ceará, Nordeste do Brasil).

Figure 1 - Location of the study area and access (East Coast, State of Ceará, Northeastern Brazil).

gião Geográfica do Jaguaribe, fazendo parte do presente estudo os Municípios da Microrregião do Litoral de Aracati: Aracati, Fortim, Icapuí e Itaiçaba; na Microrregião do Baixo Jaguaribe: Jaguaruana, Limoeiro do Norte, Palhano, Quixeré, Russas e Tabuleiro do Norte; e na Microrregião do Médio Jaguaribe: Jaguaribara e Jaguaribe. As principais vias de acesso à área são a rodovia estadual CE-040 e as rodovias federais BR-116 e BR-304

$\mathrm{Na}$ desembocadura do rio Jaguaribe está a Área de Preservação Ambiental (APA) de Canoa Quebrada, conhecida internacionalmente por sua beleza natural e seu potencial turístico, e mais a leste a APA de Ponta Grossa.O rio Jaguaribe pertence à Região Hidrográfica Atlântico Nordeste Ocidental, segundo a classificação da Agência Nacional de Águas (ANA) - Órgão Federal regulador e gestor dos recursos hídricos do Brasil - que, juntamente com a Secretaria de Recursos Hídricos (SRH) e a Companhia de Gestão de Recursos Hídricos (COGERH), são os órgãos da União e do Estado do Ceará, respectivamente, que controlam a outorga de direito de uso de suas águas de acordo com a finalidade a que se destina ${ }^{1}$.

O clima da região é o tropical quente semiárido e semiárido brando, com temperaturas médias anuais acima dos $18 \mathrm{oC}$ e chuvas concentradas de 4 a 5 meses, entre janeiro e maio. Há pouca variação da precipitação anual, verificando-se os maiores valores nas cidades litorâneas (IPECE, 2007).

\footnotetext{
${ }^{1}$ Lei Federal no 9.433/1997 e no 9.984/2000 e Lei Estadual no 14.844/2010, Decreto no 31.076/2012).
} 
A vegetação está dividida em Litorânea: Pioneira Psamófila, Vegetação Subperenifólia de Dunas, Vegetação Perinifólia de Mangue; Vegetação de Várzea: Carnaubais; Vegetação dos Tabuleiros litorâneos: Subperenefólia e subcaducifólia; e Vegetação da Caatinga: espécies arbóreas e espécies arbustivas (SEMACE, 2005; 2006).

Geologicamente, a região está situada na Província Borborema, com sua origem associada ao rifte intracontinental que compõe a Bacia Potiguar. A Litologia é formada por rochas do embasamento Pré-Cambriano e Sedimentos Cretáceos, Plio-Pleistocênicos e Recentes. Consiste dos seguintes domínios morfológicos: Relevo Litorâneo, Tabuleiros Pré-Litorâneos, Borda Norte Ocidental da Chapada do Apodi e Rochas cristalinas (Sales, 2007; Maia, 1993).

\subsection{Delineamento Metodológico}

O estudo apresenta a relação existente entre as formas de utilização do meio ambiente em razão dos ciclos econômicos do passado e sua implicação nos impactos ambientais atuais. Assim, foi feito a um só tempo o estudo da ocupação humana na zona costeira do Baixo
Jaguaribe, dos impactos ambientais individuais e em conjunto, bem como dos residuais e cumulativos decorrentes dessa ocupação, juntamente com os estudos específicos em torno dos registros geológicos da região. Em relação à natureza do trabalho, essa pesquisa possui características exclusivamente qualitativas, vez que não tem, em seus objetivos, a intenção de apresentar resultados mensuráveis quantitativamente.

Já no que se refere aos objetivos, ela pode ser considerada exploratória e descritiva. Exploratória na medida em que permitiu o aprofundamento dos temas correlacionados à temática central do trabalho; e descritiva por procurar descrever uma determinada região em suas mais significantes características, bem como apontar o resultado da ação antrópica.

Quanto aos procedimentos técnicos, optou-se pelas pesquisas bibliográfica, documental e de campo. $\mathrm{Na}$ pesquisa documental, buscou-se analisar mapas antigos do Instituto do Ceará, bem como outros mapas tematicos e imagens de satélites, para maior compreen-são das alterações da dinâmica natural da bacia hidrográfica. Por fim, na pesquisa de campo, foram realizadas entrevistas com moradores da região, além da observação simples e de levantamento fotográfico.

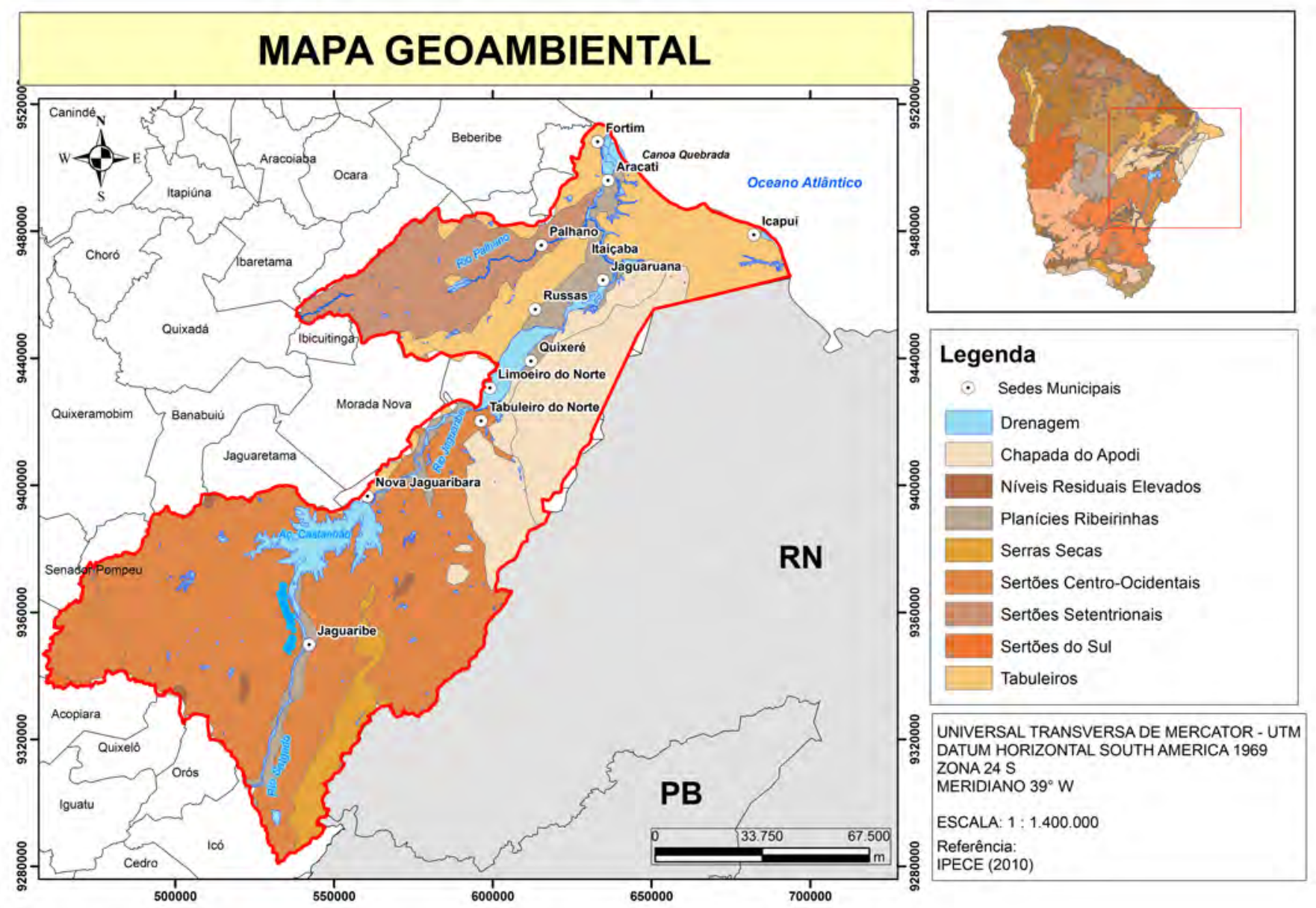

Figura 2 - Bacias Hidrográficas do Médio e Baixo Jaguaribe. (Litoral Leste, Ceará, Brasil).

Figure 2 - Watersheds of the Middle and Lower Jaguaribe. (East Coast, Ceará, Brazil). 


\section{Resultados e discussão}

\subsection{Ocupação do território jaguaribano no decorrer da história}

Em relação à chegada dos primeiros europeus em terras cearenses, os historiadores relatam o insucesso de muitas expedições em decorrência das dificuldades de navegação e climáticas e os constantes conflitos com os índios nativos, que resultaram em muitas mortes e desistências (e.g., Abreu, 1899; Studart, 1896; 1898; 1903; Thebérge, 1895).

No início, no chamado período pré-colonizador (15001530), ocorreram as primeiras expedições de reconhecimento e exploração do Pau-Brasil (Caesalpina echinata) no litoral cearense, mas somente a partir de 1600 ocorreram as primeiras expedições portuguesas de vulto no Estado.

Em 1603, o Capitão-mor Pero Coelho de Souza, morador da povoação da Paraíba, percorreu nossa costa à frente de oitenta e seis soldados e duzentos índios para descobrir nossas riquezas e tolher o comércio com os franceses. Essa expedição fundou o forte de São Lourenço, nas margens do rio Jaguaribe (e.g., Studart, 1896; 1898; Thebérge, 1895).

Nesse contexto, o rio Jaguaribe foi um importante facilitador da penetração e fixação dos colonizadores "sertão adentro"; em seus leitos secos os primeiros colonizadores foram instalando suas fazendas, lavouras e avançando seus rebanhos. Às suas margens passava a Estrada Geral do Jaguaribe, que ligava a cidade de Aracati, no litoral, ao sertão; passando pela cidade de Russas, Icó e seguindo o rio Salgado, ultrapassava a chapada do Araripe para alcançar os sertões do Pernambuco em direção à Bahia. Era a principal via de escoamento de gado e cavalos para a zona do Médio São Francisco e minerações de Minas Gerais (Studart, 1896, 1898, 1903).

A povoação do Ceará, pelo Sul, também se deu pelas incursões dos aventureiros baianos e sergipanos, ou "Homens do Rio de San Francisco" (Girão, 1949, 1986; Thebérge, 1869), que chegavam por via do sertão deserto da Paraíba e do Rio Grande e se instalavam. Nos anos seguintes, continuou o povoamento do interior e a expansão das fazendas de gado e cana-deaçúcar. As grandes secas de 1724 até 1728 e a de 1732 mataram muitos habitantes e quase todo o gado (Thebérge, 1895; Girão, 1986).

Apesar dos conflitos constantes com os índios, os períodos intercalados de secas e inundações devastadoras e as dificuldades no escoamento da produção, a região jaguaribana iniciou seu desenvolvimento econômico, chegando, no final do século XVIII, a ser uma das maiores cidades da Capitania (Brigido, 1910).

Diversos ciclos agroeconômicos marcaram o desenvolvimento da região jaguaribana no decorrer dos séculos. $\mathrm{O}$ rio Jaguaribe foi, e ainda é, palco de várias atividades antrópicas e representa um importante catalizador econômico para a região.

\subsection{A Agropastorícia}

A exploração da madeira nativa foi a primeira atividade desenvolvida na região jaguaribana, atraindo o interesse dos primeiros exploradores portugueses, espanhóis, franceses e holandeses. Em 1639, os holandeses, em guerra com a Espanha (que à época dominava Portugal), se sentiram à vontade para invadir e instalar as primeiras salinas na região da atual cidade de Aracati.

A partir de 1681, foram feitas as primeiras doações de Sesmarias pelo rei de Portugal para promover o povoamento do Vale do Jaguaribe pelos criadores de gado, dando início ao ciclo agropastoril, com as primeiras fazendas de gado, cana-de-açúcar e as primeiras indústrias de charque ${ }^{1}$ (Girão, 1986).

A cana de açúcar, na região jaguaribana, era produzida basicamente na zona litorânea, sendo beneficiada em pequenos engenhos, sobretudo para obtenção da cachaça ${ }^{2}$.

A pecuária fornecia couro para a exportação e carne para o mercado interno. As dificuldades e os prejuízos ocasionados nas longas travessias das boiadas para a venda em outras praças (Pernambuco, Bahia e até Minas Gerais), aliados às características climáticas favoráveis e à proximidade dos depósitos naturais de sal, impulsionaram o desenvolvimento da indústria do charque. (Almeida, 1887)

Aracati transformou-se em produtor de carne seca e no principal porto de exportação deste produto para as regiões produtoras de cana-de-açúcar, além de continuar a ser um ponto de apoio militar (Fortim de Aracati). O rendoso comércio de carne e couro atraía abastados senhores de locais diversos, fazendo com que Aracati fosse considerada, por longo tempo, a localidade de maior influência de formação econômica, social e política do povo cearense (e.g., Paulet, 1898; Girão, V.C, 1984).

As secas de 1777-1778 e 1790-1793 aniquilaram a florescente e rendosa indústria do charque jaguaribano. Segundo Almeida (1887: 85), a seca de 1790-1793 foi tão terrível e rigorosa “(...) que derrubou, destruio e matou quase todos os gados dos sertões desta comarca, e por isso veio a perder aquelle ramo de commercio das fabricas de carnes secas desde o anno de 1793 exclusivo, porque no anno de 1794 já não houve gados que se matar, (...)”. Assim, no final do século XVIII, tem início o ciclo do Algodão, e a Vila de Aracati se

\footnotetext{
${ }^{1}$ Carne bovina cortada em mantas, salgada e seca ao sol ou por processos afins com o objetivo de mantê-la própria ao consumo por mais tempo.

${ }^{2}$ Cachaça ou pinga, nome dado à aguardente de cana, uma bebida alcoólica tipicamente brasileira.
} 
torna um centro comercial com raio de influência até Icó e sertão adentro.

O modo de exploração da pecuária, aliado às características geológicas, geomorfológicas e climáticas da região, mostra- se de extrema relevância ao analisarmos os atuais impactos ambientais. A criação de gado era feita de maneira extensiva e os latifundiários sobrecarregavam o pasto natural (caatinga), colocando um grande número de cabeças de gado em uma mesma área. Aliado ao inadequado plano de manejo, inexistia mão de obra especializada e era comum a prática de queimadas para "limpar" o terreno. A consequência dessas práticas inadequadas de manejo por vários anos foi agravando seus efeitos com o passar dos tempos.

O desmatamento da vegetação natural e o pisoteio do gado foram provocando a degeneração do solo e a erosão do terreno, o que contribui diretamente para a diminuição da capacidade produtiva (econômica e biológica) e da disponibilidade hídrica superficial/ subterrânea, contribuindo diretamente, por fím, para o assoreamento dos cursos de água, a extinção da fauna e flora nativa e o surgimento dos efeitos da desertificação. Essa situação se mostra presente nas proximidades da cidade de Jaguaribe e nos municípios vizinhos.

O ciclo do extrativismo da cera de carnaúba teve início em meados do século XIX e era voltado, sobretudo, para o mercado externo. Trouxe rápido desenvolvimento econômico para as cidades de Limoeiro do Norte e Russas, que margeiam o rio Jaguaribe.

Os ciclos algodoeiro e extrativista também contribuíram e, de certa forma, aceleraram os atuais impactos ambientais, uma vez que as queimadas continuavam presentes como técnica de preparo do solo para plantio, causando a destruição dos micronutrientes do solo, infertilidade e erosão. A retirada de madeira e outros produtos do extrativismo vegetal contribuíram para a queda da biodiversidade e para a destruição da mata ciliar e da caatinga, contribuindo para o assoreamento dos cursos de água.

A remoção dos horizontes superficiais do solo e da mata ciliar resultaram no aumento da produção de sedimentos que se deslocaram para o rio, causando o solapamento de suas margens. Esse processo contribuiu para o rápido empobrecimento do solo e para a aceleração dos processos de desertificação, cada vez tornando mais indispensável a utilização de fertilizantes químicos, agrotóxicos e sementes geneticamente modificadas para manter os níveis satisfatórios de produção.

Nos anos 1970-1980², em face da crise econômica, fiscal e financeira nacional, têm início os primeiros

\footnotetext{
${ }^{1}$ Após o Golpe Militar em 1964, o Brasil viveu sob um regime de ditadura até 1985. Há elevação do endividamento público para manter a política econômica desenvolvida; período conhecido como "Milagre Econômico". Crescimento da indústria brasileira a taxas elevadíssimas graças ao ingresso maciço de capitais
}

projetos de expansão da produção agrícola e irrigação. $\mathrm{O}$ cultivo de arroz se destaca como atividade de maior relevância nesse processo, transformando a paisagem rural Jaguaribana, principalmente nas planícies aluviais de Morada Nova e Jaguaruana (Rolim, 2006). Grandes investimentos em obras hidráulicas, estradas, portos, capacitação técnica etc. no Estado atraíram investidores estrangeiros para a Chapada do Apodi, sobretudo para a produção da fruticultura para exportação (Gomes, 2009).

No final do séc. XX, após a criação da Superintendência do Desenvolvimento do Nordeste - SUDENE ${ }^{2}$, cresce o número de estudos integrados de planejamento a nível regional contra as secas, tendo início em 1995 a construção do Açude Castanhão (Figura 3), maior açude para usos múltiplos da América Latina, em uma parceria entre a SRH-CE (Secretaria de Recursos Hídricos do Ceará) e o DNOCS (Departamento Nacional de Obras Contra as Secas). Nesse mesmo momento histórico, entra em expansão a mineração e a produção de cerâmica na região da cidade de Russas.

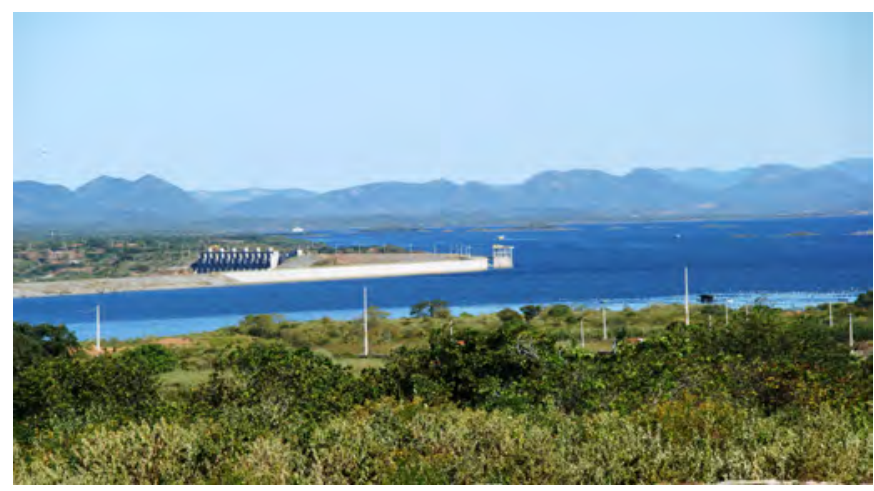

Figura 3 - Açude Castanhão. (Nova Jaguaribara, Ceará, Brasil).

Figure 3 - Castanhão Weir. (Nova Jaguaribara, Ceará, Brazil).

A construção de inúmeros reservatórios e barramentos, aliada às defasadas técnicas de irrigação, promoveu o desenvolvimento, mas provocou o desperdício de grandes volumes de água e resultou em sérios impactos ambientais. Atualmente, $90 \%$ do fluxo dos rios cearenses é controlado artificialmente e retido em barragens, açudes e represas (SRH, 2006).

estrangeiros. A partir de 1974, com a crise mundial do petróleo, a indústria de bens de consumo duráveis começa a encalhar, repercutindo na elevação nas taxas de juros, altas taxas de inflação e aumento da dívida externa.

2 A SUDENE é uma autarquia especial, administrativa e financeiramente autônoma, integrante do Sistema de Planejamento e de Orçamento Federal, criada pela Lei Complementar no 125, de 03/01/2007, com sede na cidade de Recife-PE e vinculada ao Ministério da Integração Nacional. Criada em 15/12/1959 representou uma conquista importante para o povo brasileiro, pois deu início a uma nova era, marcada pela incorporação progressiva da Região Nordeste e, em seguida, da Amazônia, ao processo de desenvolvimento nacional. (SUDENE, 2013). 
Para a construção desses açudes, foram inundadas e desmatadas extensas áreas cultiváveis; facilitando os processos erosivos do solo no entorno. Aceleraram-se os processos de salinização e eutrofização dos cursos d'água; provocam-se alterações na fauna silvestre natural local, além de interferir no transporte de sedimentos e no fluxo hídrico. Essas alterações contribuíram para a diminuição da vazão do rio, da sua capacidade de transportar sedimentos por longas distâncias e de escavar o canal, resultando na diminuição da profundidade, no assoreamento e na redução na vazão de água doce/sedimentos que chega ao estuário e ao mar, ocasionando um aumento da concentração de poluentes e, consequentemente, na redução dos recursos vivos. (Figura 4)

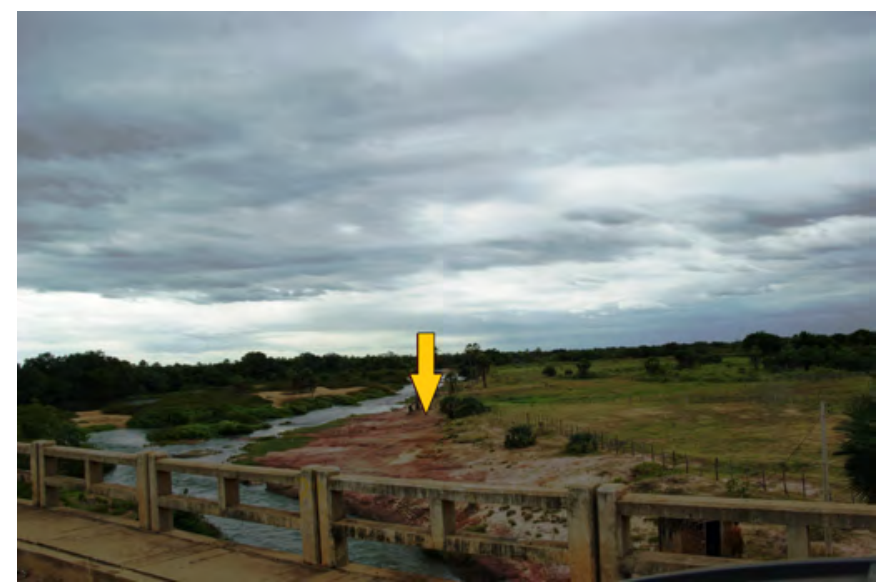

Figura 4 - Mata ciliar do rio Jaguaribe degradada. (Apodi/Limoeiro, Ceará, Brasil).

Figure 4 - Degraded riparian zone of Jaguaribe River. (Apodi/ Limoeiro, Ceará, Brazil).

\subsection{Exploração Mineral e Turismo}

Outra atividade praticada nos recentes anos com maior intensidade e que vem provocando significativas consequências ao ambiente jaguaribano é a mineração e a indústria oleira/ceramista. A falta de tecnologia de produção resulta em perda de tempo, de matéria-prima e de mão de obra, encarecendo o produto final e reduzindo sua competitividade.

Dentre as principais características da produção ceramista está a extração da argila, feita, sobretudo, horizontalmente, ficando restrita tão somente à camada superior da jazida, o que contribui para a rápida extinção da maioria dos depósitos de argila do tipo cobertura no futuro. A ineficiência térmica dos fornos de produção resulta no desperdício de lenha, exigindo maiores quantidades desse insumo. Finalmente, outro efeito danoso dessa atividade é a elevada produção de fumaça potencialmente poluente expelida pelos fornos, além de resíduos cerâmicos e esgotos provenientes da produção, vez que não são devidamente descartados para evitar a contaminação do lençol freático.
$\mathrm{O}$ desenvolvimento econômico do século $\mathrm{XX}$ e $\mathrm{XXI}^{1}$ e as políticas de apoio à intervenção privada, que tiveram início em meados do séc. XX, fomentaram o desenvolvimento do turismo na Região Costeira, intensificando a construção de grandes empreendimentos, equipamentos turísticos e imobiliários e atraindo a atenção do investimento internacional para o litoral jaguaribano, sobretudo para as cidades de Fortim e Canoa Quebrada (Dantas, 2003).

Assim, houve a aceleração da ocupação urbana e costeira, provocando alterações na paisagem natural, nos fluxos hídricos, além da especulação imobiliária. Em decorrência da falta de prévio estudo e planejamento urbano, as cidades se desenvolveram de maneira irregular, levando em consideração apenas os interesses econômico-financeiros.

Além da especulação imobiliária, que provocou sensíveis transformações no quadro socioambiental (Vasconcelos \& Coriolano, 2008); evidenciaram-se problemas com a rápida impermeabilização do solo, a contaminação de recursos hídricos, a erosão de falésias, além dos impactos com a poluição, em face da falta de infraestrutura para dispor corretamente esgotos e lixo sólido. (Figura 5)

\subsection{Produção de Energia}

Ainda no séc. XX, em meados da década de 70, diante da crise internacional do petróleo, são feitos os primeiros investimentos no Ceará para a produção em escala comercial de energia eólica e petróleo on shore. Outras duas atividades econômicas começaram a ser desenvolvidas no final do séc. XX e seguem até os dias atuais em franca expansão, propiciando desenvolvimento econômico para a região: a exploração de petróleo on shore (terrestre), na cidade litorânea de Icapuí, e as usinas eólicas, dispostas sobre as dunas de várias cidades costeiras, sobretudo no litoral de Aracati e Canoa Quebrada.

As usinas eólicas provocaram modificações na paisagem costeira e no transporte de sedimentos eólicos. Para sua instalação, foram feitas alterações na dinâmica hidrostática e aterramento de lagoas interdunares, o que pode influenciar na disponibilidade e qualidade da água doce do aquífero dunar. Além disso, a turbulência e os ruídos na área, de influência direta dos aerogeradores,

\footnotetext{
${ }^{1}$ Em 1987, Tasso Jereissati é eleito governador do Ceará pela primeira vez, autodenominado "Governo das Mudanças", planejando a abertura e o desenvolvimento da economia estadual. Em 1990, seu sucessor, Ciro Gomes, deu continuidade a seus projetos até a reeleição de Tasso em 1995, permanecendo no Governo até 2002, priorizando o aumento das receitas, visando a investimentos públicos e privados em infraestrutura e nos setores industrial e de serviços. Foram realizadas grandes obras governamentais nesse período, como: Porto do Pecém, Aeroporto Internacional de Fortaleza, Açude Castanhão, Centro Cultural Dragão do Mar e o Canal da Integração.
} 


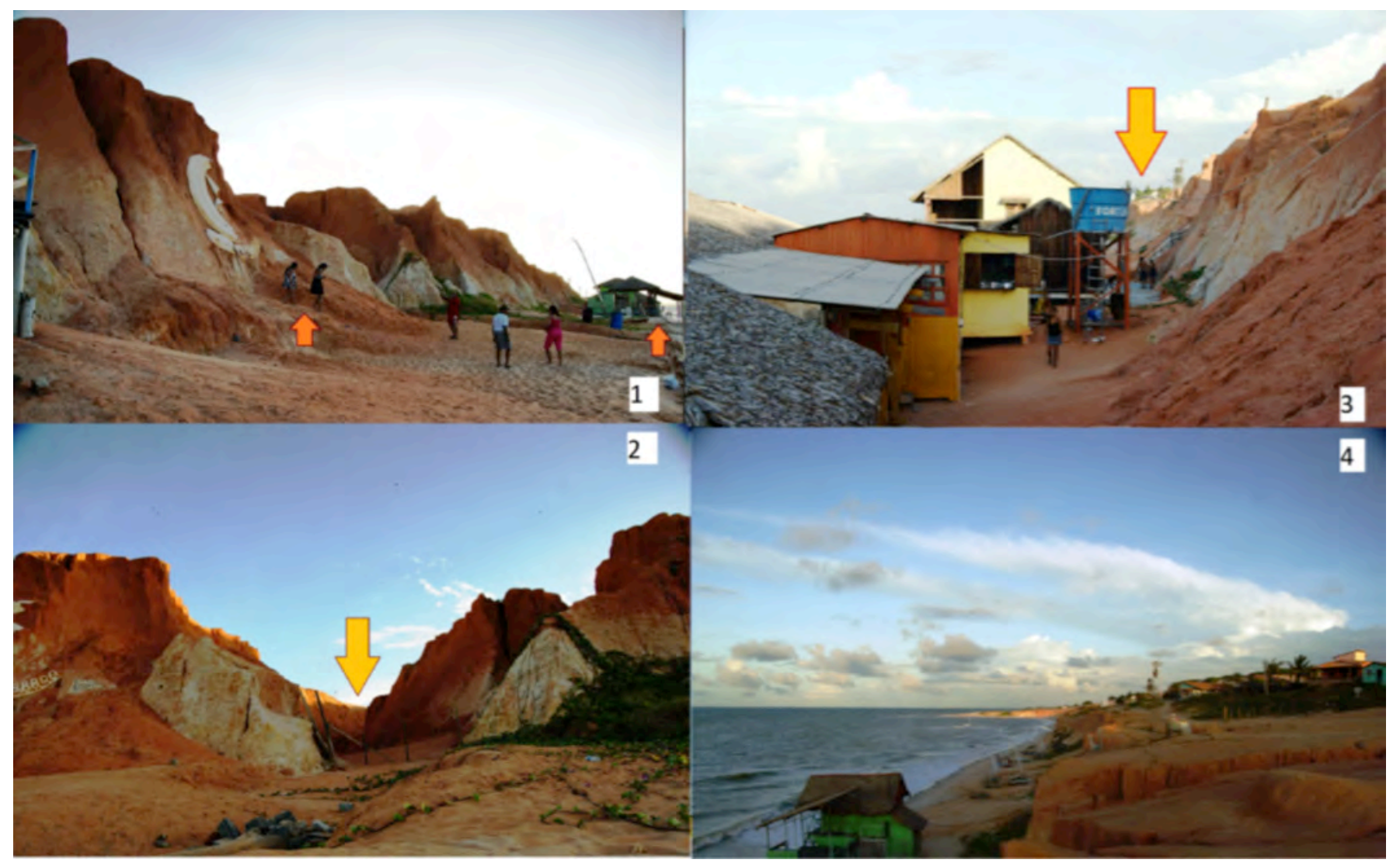

Figura 5 - 1- Pisoteamento, 2- Voçoroca em falésia, 3 e 4- Ocupação irregular em falésia. (APA de Canoa Quebrada, Ceará, Brasil).

Figure 5 - Trampling, 2 - Gully cliff, 3 and 4 -Irregular Cliff Occupation. (EPA of Canoa Quebrada, Ceará, Brazil).

podem trazer incômodos à fauna e à população do entorno.

A exploração petrolífera é responsável pela geração de grande diversidade de resíduos sólidos, semissólidos e presença de substâncias potencialmente tóxicas. A água de produção é a maior preocupação ambiental por conter quantidades variadas de sais e gases dissolvidos $\left(\mathrm{CO}, \mathrm{CO}_{2}, \mathrm{H}_{2} \mathrm{~S}\right)$, sólidos em suspensão, componentes com algum nível de radiação, metais pesados, altas concentrações de cloretos, gotículas de óleo suspensas ou emulsificadas, características que a tornam imprópria para consumo humano e animal, sobretudo em um estado que sofre com a escassez hídrica. Assim, caso não sejam tomados os devidos cuidados, os prejuízos ambientais podem ser irremediáveis.

\subsection{Aquicultura}

Por fim, o séc. XXI tem a carcinicultura como agronegócio de maior relevância econômica, colocando o Ceará como maior produtor nacional e segundo maior exportador, após o Rio Grande do Norte, sendo que, somente na região jaguaribana, existiam, em 2013, aproximadamente, 3.100 ha de produção (Paula et al, 2006, Vaz, 2011).
A carcinicultura despontou como o agronegócio do século XXI no entorno do rio Jaguaribe. Apesar de algumas fazendas terem sito construídas em antigas salinas, para a construção dos tanques é necessária a remoção da cobertura vegetal e da mata ciliar, acelerando os processos de desmatamento e erosão. Na fase de instalação, são feitas mudanças na drenagem no curso do rio, alterando as características físico-químicas do substrato e desviando/impedindo o fluxo das marés.

O descarte não tratado dos efluentes da produção é responsável pelo acúmulo de matéria orgânica e substâncias tóxicas no sedimento, ocasionando a morte das espécies da fauna e flora dos estuários, manguezais e ecossistemas adjacentes; bem como no assoreamento e na perda da qualidade das áreas de estuário e/ou de mangue pela grande quantidade de material em suspensão carreado por seus efluentes durante as trocas de água.

\section{Conclusões}

Não há que se falar na ocupação da Capitania do Ceará sem ressaltar a importância que o rio Jaguaribe teve para esse processo histórico, sobretudo devido à 
Tabela 1 - Tabela cronológica de ciclos econômicos e possíveis impactos ambientais.

Table 1 - Chronological table of the economic cycle and possible environmental impacts.

\begin{tabular}{|c|c|c|}
\hline CICLO ECONÔMICO & ATIVIDADE & POSSÍVEIS IMPACTOS AO AMBIENTE \\
\hline (1) & $\begin{array}{l}\text { Retirada de madeira nativa, } \\
\text { Salinas, } \\
\text { Pecuária, } \\
\text { Indústria saladeril (Charque). } \\
\text { Agricultura (Cana-de-açúcar e algodão). } \\
\text { Extrativismo vegetal (Cera de Carnaúba); } \\
\text { Agricultura irrigada (cultivo de arroz e } \\
\text { fruticultura para exportação); } \\
\text { Açudagem. }\end{array}$ & $\begin{array}{l}\text { - Sobrecarga do uso do solo (sobrepastoreio), } \\
\text { - Desmatamento da mata natural (Caatinga), } \\
\text { - Degeneração da cobertura vegetal, } \\
\text { - Aumento dos processos erosivos, } \\
\text { - Solapamento das margens do rio, } \\
\text { - Diminuição da capacidade produtiva (econô- } \\
\text { mica e biológica) e dos recursos hídricos } \\
\text { superficiais e subterrâneos, } \\
\text { - Assoreamento dos cursos d'água e a extinção } \\
\text { da fauna e flora Nativa. (Pinheiro et al, 2009; } \\
\text { Gomes, 2009; Guerra, 2009; Souza et al., } \\
\text { 2006) } \\
\text { - Diminuição da vazão do rio, } \\
\text { - Alteração do fluxo sedimentológico em dire- } \\
\text { ção ao ambiente estuarino e costeiro; } \\
\text { - Erosão costeira (Lacerda et al, 2002) } \\
\text { - Diminuição da qualidade da água (aumento da } \\
\text { salinidade e concentração de poluentes) (Maia } \\
\text { et al, 2005) }\end{array}$ \\
\hline $\begin{array}{c}\text { EXPLORAÇÃO MINERAL } \\
\text { 1950-2011 }\end{array}$ & Indústria cerâmica e mineração. & $\begin{array}{l}\text { - Desmatamento, } \\
\text { - Extração mineral desordenada, } \\
\text { - Erosão do solo, } \\
\text { - Perda gradativa da biodiversidade, (Pessoa, } \\
\text { 2004) } \\
\text { - Contaminação de reservas de água (resíduos } \\
\text { potencialmente poluentes e fumaça). }\end{array}$ \\
\hline $\begin{array}{l}\text { TURISMO } \\
\text { 1970-2011 }\end{array}$ & $\begin{array}{l}\text { Construção de Hotéis, Resorts, casas de } \\
\text { veraneio, infraestrutura de apoio e aumento } \\
\text { da ocupação urbana. }\end{array}$ & $\begin{array}{l}\text { - Degradação da vegetação e da paisagem natural } \\
\text { (construções, pisoteio, circulação de veículos) } \\
\text { - Poluição do manancial hídrico (produção de } \\
\text { resíduos sólidos e esgotos) (Matanó et al, } \\
\text { 2003) }\end{array}$ \\
\hline $\begin{array}{l}\text { PRODUÇÃO DE ENERGIA. } \\
\text { 1990-2011 }\end{array}$ & $\begin{array}{l}\text { Parques eólicos; } \\
\text { Exploração de petróleo on shore }\end{array}$ & $\begin{array}{l}\text { - Desmatamento de dunas fixas, } \\
\text { - Alterações paisagísticas, geotécnicas, morfo- } \\
\text { lógicas e no transporte de sedimentos eólicos, } \\
\text { - Alteração na dinâmica hidrostática e disponi- } \\
\text { bilidade de água doce do aquífero dunar, } \\
\text { - Aumento da turbulência e ruídos } \\
\text { - Poluição do solo e dos recursos hídricos } \\
\text { (produção de resíduos sólidos ou semissólidos } \\
\text { tóxicos) }\end{array}$ \\
\hline $\begin{array}{l}\text { AQUICULTURA } \\
\text { 1990-2011 }\end{array}$ & Cultivo de peixes e camarões em cativeiro. & $\begin{array}{l}\text { - Desmatamento, } \\
\text { - Erosão, } \\
\text { - Assoreamento das áreas de estuário, (Lacer-da } \\
\text { et al, 2002) } \\
\text { - Mudanças nas características físico-químicas } \\
\text { do substrato e desvio/impedimento do fluxo } \\
\text { das marés }\end{array}$ \\
\hline
\end{tabular}


valorização de seu potencial pastoril e agrícola, que definiu sua ocupação desde o século XVII.

Com o decorrer dos anos, entretanto, a ocupação da região jaguaribana se deu de maneira acelerada e desordenada, levando em consideração apenas o interesse econômico dos governantes e proprietários de terras. Muito pouco foi planejado ou ponderado a respeito dos impactos ambientais residuais ou cumulativos gerados pelo conjunto das atividades econômicas empreendidas durante vários anos e suas implicações para as futuras gerações.

Assim, os diferentes ciclos econômicos induziram impactos relevantes na bacia do Jaguaribe, designadamente: a) Pecuária e agricultura: desmatamento da mata natural (caatinga), degeneração da cobertura vegetal e dos recursos hídricos, erosão e assoreamento dos cursos d'água; b) Mineração: extração mineral desordenada, poluição do manancial hídrico e produção de resíduos poluentes e fumaça; c) Turismo: Degradação da vegetação e da paisagem natural, poluição dos recursos hídricos e produção de resíduos sólidos; d) Produção de energia: Desmatamento, alterações paisagísticas, geotécnicas, morfológicas e no transporte de sedimentos eólicos, poluição do solo e dos recursos hídricos; e) Aquicultura: desmatamento, erosão e assoreamento das áreas de estuário, alterações físico-químicas do substrato e do fluxo de marés.

\section{Referências}

Abreu, C. de (1899) - Sobre uma Historia do Ceará. Revista do Instituto do Ceará, XIII:22-33, Fortaleza, CE, Brasil. Disponível on-line em http://memoria.bn.br/DocReader/DocReader.aspx? $\mathrm{bib}=144843 \& \mathrm{PagFis}=3482$.

Almeida, M.E. (1795 [1887]) - Registro de memória dos principaes estabelecimentos, factos e casos raros accontecidos nesta Villa de Santa Cruz do Aracaty, feita segundo a ordem de S.M., de 27 de Julho de 1782 pelo Vereador Manoel Esteves d'Almeida desde a fundação da dita Villa, até ao anno presente de 1885 [gralha tipográfica; é 1795]. Revista Instituto do Ceará, I: 83-86, Fortaleza, CE, Brasil. Disponível on-line em http://memoria. bn.br/DocReader/DocReader.aspx?bib=144843\&PagFis=75

Brígido, J.A. (1910) - A Capitania do Ceará. Seu commercio. Revista do Instituto do Ceará, XXIV:172-185, Fortaleza, CE, Brasil. Disponível on-line em http://portal.ceara.pro.br/index. php?option=com_content $=$ article $\& \mathrm{id}=33653: 1910$-a-capitaniado-ceara-seu-commercio\&catid $=462 \&$ Itemid $=101$

Dantas, E.W.C. (2003) - Histórico da ocupação da zona costeira. In: Alberto Alves Campos (org.), A zona costeira do Ceará: Diagnóstico para a gestão integrada, pp.138-210, Editora Aquasis, Fortaleza, CE, Brasil. ISBN: 8589491013

Girão, R. (1949) - Bandeirismo Baiano e povoamento do Ceará, 20p., Instituto do Ceará, Fortaleza, CE, Brasil.

Girão, R. (1986) - A marcha do povoamento do vale do Jaguaribe (1600-1700). 89p., Fortaleza, CE, Brasil.

Girão, V. C.(1984) - As oficinas ou charqueadas no Ceará. 154p., Secretaria de Cultura e Desporto, Fortaleza, CE, Brasil.

Gomes, I.R. (2009) - As novas regiões produtivas agrícolas : o caso do Baixo Jaguaribe (CE) -Vale do Açu (RN). IDeAS - Revista
Conclui-se, portanto, ser importante a avaliação sistêmica e cada vez mais abrangente da qualidade ambiental, antes de autorizar uma nova utilização ou atividade às margens do rio Jaguaribe. Essa avaliação pode se mostrar, por fim, como uma importante ferramenta de apoio aos órgãos licenciadores, a fim de que possam tomar suas decisões de forma mais racional, de modo a não serem menosprezados impactos e fatores de tensão importantes, bem como a capacidade do ambiente de absorver esses impactos, podendo comprometer seu uso sustentável para as futuras gerações.

\section{Agradecimentos}

O presente estudo é parte integrante da dissertação de Mestrado em Ciências Marinhas Tropicais e foi proposto em resposta à participação de pesquisadores do Ceará na rede de pesquisa denominada BrasPor (http://www.redebraspor.com). Trata-se de um grupo de pesquisa informal, que pretende criar sinergias a partir da colaboração entre cientistas dedicados ao estudo de sistemas diferenciados e contrastantes (dos pontos de vista físico e humano) e com formações diversificadas (das Ciências Físicas e Naturais e das Ciências Humanas e Sociais). Agradeço o apoio do Instituto Nacional de Ciência e Tecnologia de Transferência de Materiais Continente-Oceano (INCT-TMCOcean), ao editor e aos avaliadores da Revista de Gestão Costeira Integrada RGCI/JICZM, por suas preciosas orientações e sugestões.

Interfaces em Desenvolvimento, Agricultura e Socie-dade (ISSN 1984-9834), 3(2):288-323, Rio de Janeiro, RJ, Brasil. Disponível on-line em http://r1.ufrrj.br/cpda/ideas/revistas/ v03/n02/IDeAS-v03_n02-Artigo_IARA_GOMES.pdf

Guerra, M.D.F. (2009) - A problemática da desertificação nos sertões do médio Jaguaribe, Ceará: o contexto do Município de Jaguaribe. 171p., Dissertação de Mestrado, Universidade Estadual do Ceará, Fortaleza, CE, Brasil. Disponível on-line em $\mathrm{http} / / /$ www.uece.br/mag/dmdocuments/maria_daniely_dissertac ao.pdf

IPECE (2007) - Tipos Climáticos. In: Ceará em Mapas, Instituto de Pesquisa e Estratégia Econômica do Ceará (IPECE), Governo do Estado do Ceará, Fortaleza, $\mathrm{CE}$, Brasil. Disponível on line em: http://www2.ipece.ce.gov.br/atlas/capitulo1/12/126.htm.

Lacerda, L.D.; Kremer, H.H.; Kjerfve, B.; Salomons, W.; Crossland, J.I.M. \& Crossland, C.J. (2002) - South American Basins: LOICZ Global Change Assessment and Synthesis of River Catchment-Coastal Sea Interaction and Human Dimenson. 48p., LOICZ Reports and Studies, Amsterdam, Holanda. http://www.loicz.org/imperia/md/content/loicz/print/anualreport s/ar2001.pdf

Maia, L.P.(1993) - Controle tectônico e evolução geológica sedimentológica da região da desembocadura do rio Jaguaribe. 144p., Dissertação de Mestrado, Departamento de Geologia, Universidade Federal de Pernambuco, Recife, PE, Brasil. Não publicado.

Maia, L.P.; Lacerda, L.D. de; Monteiro, L.H.U.; Souza, G.M. (2005). Estudo das áreas de manguezais do nordeste do Brasil. 62p., Instituto de Ciências do Mar; Sociedade Internacional para 
ecossistemas de manguezal, Fortaleza, CE, Brasil. Disponível on line em: http://www.institutomilenioestuarios.com.br/pdfs/ Produtos/002/046Mangrove_distribution_in_NE_Brasil_ej05_1. pdf

Matanó, A.; Lacerda, L.D.; Marins, R.V. (2003) - Estimativa das emissões de carbono, nitrogênio e fósforo para o estuário do rio Jaguaribe (CE). Anais do $6^{\circ}$ Congresso de Ecologia do Brasil, VI:163-164, Fortaleza, CE, Brasil. Disponível on line em: http://www.seb-ecologia.org.br/anais/3.pdf

Paula, D.P.; Morais, J.O.; Pinheiro, L.S. (2006) - Análise geoambiental do estuário do rio Jaguaribe-CE: tensores naturais e antrópicos. Anais do $6^{\circ}$ Simpósio Nacional de Geomorfologia, VI:1-11, Goiânia, GO, Brasil. Disponível on line em: http://www.seb-ecologia.org.br/anais/3.pdf

Paulet, A.J.S. (1898) - Descripção Geográfica Abreviada da Capitania do Ceará. Revista do Instituto do Ceará, XII:5-33, Fortaleza, CE, Brasil. Disponível on-line em http://memoria. bn.br/DocReader/DocReader.aspx?bib=144843\&PagFis=3182

Pessoa, J.M.A.D.P. (2004) - Tecnologias e técnicas apropriadas para o desenvolvimento sustentável: o caso da indústria cerâmica de Russas-CE. 104p. Dissertação de Mestrado, PRODEMA, Universidade Federal do Ceará, Fortaleza, CE, Brasil. Não publicado.

Pinheiro, R.A.B.; Gomes Neto, A.O.; Guerra, M.D.F. (2009) Processo de degradação ambiental/desertificação e a pecuária no Distrito de Feiticeiro - Município de Jaguaribe/Ceará. Anais do $8^{\circ}$ Simpósio Nacional de Geografia Física Aplicada, s/pag., Viçosa, MG, Brasil. Disponível on line em http://www.geo. ufv.br/simposio/simposio/trabalhos/trabalhos_completos/eixo11 /074.pdf

Rolim, J.B de Sousa (2006) - Sistemas técnicos e sustentabilidade: Desafios no Perímetro Irrigado De Morada Nova (PIMM), Ceará. 131p., Dissertação de Mestrado. Universidade Estadual do Ceará, Fortaleza, CE. Disponível on line em http://www.livrosgratis.com.br/arquivos_livros/cp013229.pdf

Sales, V.C. (2007) - Evolução morfoestrutural do relevo da margem continental do Estado do Ceará, Nordeste do Brasil. Revista Caminhos de Geografia (ISSN: 1678-6343), VIII(20):1-21, Uberlândia, MG, Brasil. Disponível on line em: http://www.seer.ufu.br/index.php/caminhosdegeografia/article/d ownload/15469/8757

SEMACE (2005) - Mapeamento das unidades geoambientais da zona costeira do Estado do Ceará. Superintendência Estadual do Meio Ambiente (SEMACE), Governo do Estado do Ceará , Fortaleza, Ceará, Brasil. Disponível on line em: $\mathrm{http}: / /$ gerco.semace.ce.gov.br/mapa.asp?cab=mapas\&id=8
SEMACE (2006). Zoneamento Ecológico-Econômico do Ceará Zona Costeira.147p., Superintendência Estadual do Meio Ambiente (SEMACE), Governo do Estado do Ceará, Fortaleza, CE, Brasil.

Souza, M.J.N.D.; Morais, J.O.D.; Lima, L.C. (2006) - Panorama da degradação ambiental, desertificação e entraves ao desenvolvimento sustentável do Ceará. In: Daniel Rodrigues de Carvalho Pinheiro (org), Desenvolvimento Sustentável: desafios e discussões, pp.33-55, ABC Editora, Fortaleza, CE, Brasil. ISBN: 85-7536-181-3.

SRH (2006) - Planejamento Estratégico dos Comitês de Bacias Hidrográficas do Estado do Ceará. 120p., SRH - Secretaria dos Recursos Hídricos do Ceará, Fortaleza, CE, Brasil. Disponível on line em: http://www.srh.ce.gov.br/images/documentos/ planejamento_estrategico_comite_bacias 1012008163333.pdf

Studart. G.B. de. (1896) - Datas e factos para a história do Ceará. [Versão fac-simile de 2001], 526p., Ed. Fundação Waldemar Alcântara, Fortaleza, CE, Brasil.

Studart. G.B. de. (1898) - Para a Historia do Aracaty. Termo de vereação da Camara em 17 de Setembro de 1785. (da collecção G. Stuudart). Revista do Instituto do Ceará, XII(IV):266-270, Fortaleza, CE, Brasil. Disponível on line em: http://memoria. bn.br/DocReader/DocReader.aspx?bib=144843\&PagFis=3445

Studart. G.B. de. (1903) - Francisco Pinto e Luiz Figueiras: o mais antigo documento existente da história do Ceará. Revista do Instituto do Ceará, XVII:51-96, Fortaleza, Ceará, Brasil. Disponível on line em: http://portal.ceara.pro.br/index. php?option $=$ com_content $\&$ view $=$ article $\&$ id $=33260: 1903$ francisco-pinto-e-luiz-figueira\&catid $=449 \&$ Itemid $=101$

SUDENE Superintendência do Desenvolvimento do Nordeste (2013) - A Contribuição da SUDENE ao desenvolvimento do Brasil, 8p., Brasília, DF, Brasil. Disponível on line em: http://www.sudene.gov.br/sudene\#instituicao\%20sudene

Thebérge, P.F. (1869/1973) - Esboço histórico sobre a província do Ceará. II:218. $2^{\mathrm{a}}$ ed. (1973), Editora Henriqueta Galeno. Fortaleza, CE, Brasil.

Thebérge, P.F. (1895) - Esboço histórico sobre a província do Ceará. [Versão fac-simile de 2001]. III:266p. Editora Fundação Waldemar Alcantara, Fortaleza, CE, Brasil.

Vaz, M. (2011) - Sustentabilidade e ideologização. 32p. Jornal O POVO (ISSN: 15176819), Caderno Pesca e Aquicultura, Fortaleza, CE, Brasil.

Vasconcelos, F.P.; Coriolano, L.N.M.T. (2008) - Impactos Sócio ambientais no litoral Um foco no turismo e na gestão integrada da zona costeira no estado do Ceara/Brasil. Revista da Gestão Costeira Integrada, 8(2):259-275. DOI: 10.5894/rgci134 